\title{
HUBUNGAN PERILAKU PENCEGAHAN TERHADAP KEJADIAN AKNE VULGARIS PADA SISWA KELAS X SMK NEGERI TANJUNGSARI LAMPUNG SELATAN
}

\author{
Hernowo Anggoro Wasono ${ }^{1}$, Nopi Sani ${ }^{2}$, Yuyun Andriyani ${ }^{3}$
}

${ }^{1}$ Departemen Kedokteran Keluarga Universitas Malahayati

${ }^{2}$ Dosen Fakultas Kedokteran Universitas Malahayati

${ }^{3}$ Program Studi Kedoktean Fakultas Kedokteran Universitas Malahayati

Email: Yuyunandriyani98@gmail.com

\section{ABSTRACT : THE CORRELATION BETWEEN PREVENTION OF OCCURRENCE ACNE VULGARIS IN VOCATIONAL STUDENT CLASS X AFFAIRS TANJUNGSARI SOUTH LAMPUNG}

Background: Acne Vulgaris one serious health problems for some people with a marked presence of inflammation and recurrences are frequent. Approximately $85 \%$ of the incidence of acne vulgaris appear at the age of 12 to 25 years. Behavioral prevention of acne vulgaris is necessary especially in adolescents.

Purpose: To determine the correlation between preventive behavior to the occurrence of acne vulgaris in class $x$ SMK Students Tanjungsari South Lampung in 2020.

Methods: This type of research is observational analytic study using cross sectional design. The sample in this research is class X SMK Tanjungsari South Lampung in 2020 as many as 77 respondents who meet the inclusion and exclusion criteria. Data obtained through questionnaires filled preventive behavior and physical examination. Terknik statistical data analysis using Spearman's test.

result: There is a significant correlation to the occurrence of behavioral prevention of acne vulgaris wherein Spearman test calculations obtained a significance level of 0.000 , which means smaller than the value of $p=0.05$ with value of $r x y=0.666$ which means it is in the interval from 0.600 to 0.799 in the category of a strong relationship and has a negative correlation direction. That is the trade-offs between behavioral variables prevention of occurrence of acne vulgaris, meaning that students who perform well prevention behaviors, there was no incidence of acne vulgaris.

Conclution: there is a significant relationship of behavior prevention on the incidence of acne vulgaris. The results of the test of spearman showed a significance level of $0,000<0,05$ with a value of $r x y=0,600$ and has a direction of the correlation negative. Students are expected to be able to pay attention about the behavior of prevention of acne vulgaris that can suppress the onset of acne vulgaris.

Keywords : Acne Vulgaris, Behavior Prevention, Students

Hernowo Anggoro Wasono ${ }^{1}$, Nopi Sani ${ }^{2}$, Yuyun Andriyani ${ }^{3}$

${ }^{1}$ Departemen Kedokteran Keluarga Universitas Malahayati

${ }^{2}$ Dosen Fakultas Kedokteran Universitas Malahayati

${ }^{3}$ Fakultas Kedokteran Universitas Malahayati. Email: Yuyunandriyani98@gmail.com 


\section{INTISARI : HUBUNGAN PERILAKU PENCEGAHAN TERHADAP KEJADIAN AKNE VULGARIS PADA SISWA KELAS X SMK NEGERI TANJUNGSARI LAMPUNG SELATAN}

Latar Belakang : Akne Vulgaris salah satu masalah kesehatan yang cukup serius bagi sebagian orang dengan ditandai adanya inflamasi dan terjadi kekambuhan yang sering. Sekitar $85 \%$ kejadian akne vulgaris muncul saat usia 12 sampai 25 tahun. Perilaku pencegahan akne vulgaris sangat dibutuhkan terutama pada remaja.

Tujuan : Untuk mengetahui hubungan perilaku pencegahan terhadap kejadian akne vulgaris pada Siswa Kelas X SMK Negeri Tanjungsari Lampung Selatan Tahun 2020.

Metodologi : Jenis penelitian yang digunakan adalah penelitian observasional analitik dengan menggunakan rancangan penelitian cross sectional. Sampel dalam penelitian ini yaitu siswa kelas X SMK Negeri Tanjungsari Lampung Selatan Tahun 2020 sebanyak 77 responden yang memenuhi kriteria inklusi dan ekslusi. Data diperoleh melalui mengisi kuesioner perilaku pencegahan dan pemeriksaan fisik. Terknik analisis data menggunakan uji statistic Spearman.

Hasil : Terdapat hubungan signifikan perilaku pencegahan terhadap kejadian akne vulgaris dimana dari perhitungan uji spearman didapatkan tingkat signifikan dan mempunyai arah korelasi negative. Artinya hubungan yang tidak searah antara variabel perilaku pencegahan terhadap kejadian akne vulgaris, artinya siswa yang melakukan perilaku pencegahan dengan baik, tidak ditemukan kejadian akne vulgaris.

Kesimpulan : Terdapat hubungan signifikan perilaku pencegahan terhadap kejadian akne vulgaris. Hasil uji spearman didapatkan tingkat signifikansi sebesar 0,000 0,05 dengan nilai rxy=0,600 dan mempunyai arah korelasi negative. Diharapkan siswa untuk dapat memperhatikan tentang perilaku pencegahan akne vulgaris supaya dapat menekan timbulnya akne vulgaris.

Kata kunci : Akne Vulgaris, Perilaku Pencegahan, siswa

Hernowo Anggoro Wasono ${ }^{1}$, Nopi Sani ${ }^{2}$, Yuyun Andriyani ${ }^{3}$

${ }^{1}$ Departemen Kedokteran Keluarga Universitas Malahayati

${ }^{2}$ Dosen Fakultas Kedokteran Universitas Malahayati

${ }^{3}$ Fakultas Kedokteran Universitas Malahayati. Email: Yuyunandriyani98@gmail.com 


\section{PENDAHULUAN}

Akne Vulgaris salah satu masalah kesehatan yang cukup serius bagi sebagian orang dengan ditandai adanya inflamasi dan terjadi kekambuhan yang sering. Sekitar $85 \%$ kejadian akne vulgaris muncul saat usia 12 sampai 25 tahun, saat ini dapat terjadi sebelum memasuki usia 12 tahun dikarenakan masa pubertas yang terjadi lebih awal : Gollnick dan Dreno (2015) dalam Wardhani dan Sulistiyaningsih (2019). Akne vulgaris adalah penyakit kulit yang paling banyak terjadi dan ditandai dengan bintik kecil seperti komedo hingga bintik besar berisi nanah pada bagian pilosebaseus (folikel rambut, pangkal rambut dan kelenjar sebaseus) : Masterson (2018) dalam Wardhani dan Sulistyaningsih (2019). .

Prevalensi akne vulgaris dari populasi global mempengaruhi 9,4\% dan merupakan penyakit paling umum ke-8 di dunia. Dalam studi epidemiologi akne vulgaris terjadi pada remaja pubertas dan laki-laki dengan jumlah terbanyak. Hasil data laporan penelitian oleh Dermatologi Kosmetik Indonesia menunjukkan $60 \%$ penderita akne vulgaris pada tahun 2006, 80\% pada tahun 2007, dan $90 \%$ pada tahun 2009. Akne vulgaris paling banyak terjadi pada laki-laki $(61,2 \%)$ dibandingkan dengan perempuan (38,8\%) (Sampelan et al., 2017). Di Indonesia, akne vulgaris adalah suatu penyakit kulit yang paling umum terjadi sekitar $85-100 \%$ selama masa hidup seseorang. kejadian tertinggi pada wanita usia 14 sampai 17 tahun, berkisar $83-85 \%$, dan pada pria usia 16 sampai 19 tahun dengan berkisar 95-100\%.

Akne vulgaris dapat dicegah dengan cara menghindari terjadinya peningkatan jumlah lipid pada sebum, menghindari terjadinya faktor yang dapat memicu misalnya pola perilaku hidup sehat, olahraga yang teratur, mengindari stress, menggunakan kosmetik secukupnya, memicu terjadinya kelenjar minyak berlebihan, memberi informasi yang cukup kepada penderita akne vulgaris mengenai penyebab penyakit, pencegahan, dan cara maupun lama pengobatannya serta prognosisnya. Perilaku dapat di artikan suatu kegiatan atau aktifitas organisme yang bersangkutan. Perilaku pencegahan yang kurang baik tersebut dapat menyebabkan timbulnya akne vulgaris. Terbentuknya perilaku seseorang dipengaruhi oleh peran pengetahuan. Perilaku dimulai dari tahu dahulu terhadap suatu objek yang telah dipelajari sebelumnya. Perilaku yang didasari oleh pengetahuan lebih baik dari pada perilaku yang tidak didasari oleh pengetahuan. Berdasarkan presurvey yang dilakukan pada bulan September 2019 di SMK Negeri tanjungsari Lampung Selatan dengan teknik observasi yang dilakukan pada kelas $\mathrm{x}$ banyak didapatkan siswa yang menderita akne vulgaris baik dari siswa laki-laki maupun perempuan. Berdasarkan latar belakang diatas, maka peneliti tertarik untuk melakukan penelitian mengenai hubungan perilaku pencegahan terhadap kejadian akne vulgaris pada siswa kelas X SMK Negeri Tanjungsari Lampung Selatan Tahun 2020.

\section{METODE PENELITIAN}

Jenis penelitian yang
digunakan adalah penelitian
observasional menggunkan metode
analitik dengan menggunakan

Hernowo Anggoro Wasono ${ }^{1}$, Nopi Sani ${ }^{2}$, Yuyun Andriyani ${ }^{3}$

${ }^{1}$ Departemen Kedokteran Keluarga Universitas Malahayati

${ }^{2}$ Dosen Fakultas Kedokteran Universitas Malahayati

${ }^{3}$ Fakultas Kedokteran Universitas Malahayati. Email: Yuyunandriyani98@gmail.com 
rancangan cross sectional melalui kuesioner perilaku pencegahan yang sudah dilakukan uji validitas dan realibilitas dengan hasil valid dan pemeriksaan fisik. Penelitian ini telah dilakukan uji plagiarisme dengan hasil 13\%. Penelitian ini di lakukan di SMK Negeri Tanjungsari Lampung Selatan, sedangkan waktu penelitiannya adalah Februari 2020.

Sampel dalam penelitian ini adalah siswa kelas X SMK Negeri Tanjungsari Lampung Selatan Tahun 2020.

HASIL PENELITIAN

Tabel 1. Karakteristik Responden
Kriteria inklusi pada penelitian ini adalah Seluruh siswa kelas X SMK Negeri Tanjungsari Tahun 2020 dan siswa laki-laki dan perempuan usia 15-18 tahun. Kriteria ekslusi pada penelitian ini adalah siswa laki-laki dan perempuan usia < 15 tahun dan $>18$ tahun, tidak sedang menderita penyakit kulit lain berupa erupsi akneinformis, akne rosasea, dermatitis perioral, moluskulum kontagiosum dan folikulitis.

\begin{tabular}{cccc}
\hline $\begin{array}{c}\text { Karakteristik } \\
\text { responden }\end{array}$ & Umur & Jumlah & Persentase \\
\hline 1. Umur & 15 & 38 & $49.4 \%$ \\
& 16 & 34 & $44.2 \%$ \\
& 17 & 4 & $5.2 \%$ \\
& 18 & 1 & $1.3 \%$ \\
\hline 2. Jenis Kelamin & Total & 77 & $100 \%$ \\
\hline & Laki-laki & 37 & $48.1 \%$ \\
\hline & Perempuan & 40 & $51.9 \%$ \\
\hline
\end{tabular}

Berdasarkan tabel di atas diketahui bahwa distribusi frekuensi responden berdasarkan umur sebagian besar berumur 15 tahun $(49,4 \%)$ dan berumur 16 tahun
(44,2\%), sedangkan distribusi frekusnei responden berdasarkan jenis kelamin mayoritas responden berjenis kelamin perempuan $(51,9 \%)$.

\section{Tabel 2. Kejadian Akne Vukgaris}

\begin{tabular}{ccc}
\hline Kejadian Akne Vulgaris & Jumlah & Persentase \\
\hline Akne Vulgaris & 45 & $58.4 \%$ \\
Tidak Akne Vulgaris & 32 & $41.6 \%$ \\
\hline Total & 77 & $100 \%$ \\
\hline
\end{tabular}

Hernowo Anggoro Wasono ${ }^{1}$, Nopi Sani ${ }^{2}$, Yuyun Andriyani ${ }^{3}$

${ }^{1}$ Departemen Kedokteran Keluarga Universitas Malahayati

${ }^{2}$ Dosen Fakultas Kedokteran Universitas Malahayati

${ }^{3}$ Fakultas Kedokteran Universitas Malahayati. Email: Yuyunandriyani98@gmail.com 
Berdasarkan tabel di atas diketahui bahwa distribusi frekuensi responden berdasarkan kejadian akne vulgaris sebanyak 45 responden dengan persentase $(58,4 \%)$, dan sebanyak 32 responden dengan tidak akne vulgaris dengan persentase $(41,6 \%)$.

Tabel 3. Perilaku Pencegahan

\begin{tabular}{ccc}
\hline Kejadian Akne Vulgaris & Jumlah & Persentase \\
\hline Baik & 37 & $48.1 \%$ \\
Tidak Baik & 40 & $51.9 \%$ \\
\hline Total & 77 & $100 \%$ \\
\hline
\end{tabular}

Berdasarkan tabel di atas diketahui bahwa distribusi frekuensi responden berdasarkan perilaku pencegahan baik sebanyak 37 siswa dengan persentase $(48,1 \%)$ dan perilaku pencegahan yang tidak baik sebanyak 40 responden dengan persentase $(51,9 \%)$.

Tabel 4. Hubungan Perilaku Pencegahan Terhadap Kejadian Akne Vulgaris Pada Siswa SMK Negeri Tanjungsari Lampung Selatan Tahun 2020.

\begin{tabular}{|c|c|c|c|c|}
\hline & & & $\begin{array}{c}\text { Kejadian } \\
\text { Akne Vulgaris }\end{array}$ & $\begin{array}{c}\text { Perilaku } \\
\text { Pencegahan }\end{array}$ \\
\hline \multirow{6}{*}{$\begin{array}{c}\text { Spearman's } \\
\text { rho }\end{array}$} & Kejadian Alne & Correlation & 1 & $-0,666^{n}$ \\
\hline & & Sig. (2-tailed) & & 0,000 \\
\hline & & $\mathrm{N}$ & 77 & 77 \\
\hline & $\begin{array}{l}\text { Perilaku } \\
\text { Pencegahan }\end{array}$ & $\begin{array}{l}\text { Correlation } \\
\text { Coefficient }\end{array}$ & $-0,666^{* m}$ & 1 \\
\hline & & Sig. (2-tailed) & 0,000 & $\cdot$ \\
\hline & & $\mathrm{N}$ & 77 & 77 \\
\hline
\end{tabular}

Berdasarkan tabel di atas dengan perhitungan uji spearman didapatkan tingkat signifikansi sebesar 0,000 yang artinya lebih kecil dari nilai $\mathrm{p}=$ 0,05 dengan nilai rxy $=0,666$ yang artinya berada pada interval 0,6000,799 masuk kategori hubungan yang kuat (Sugiyono, 2009) dan mempunyai arah korelasi negative. Artinya hubungan yang tidak searah antara variabel perilaku pencegahan terhadap kejadian akne vulgaris, artinya siswa yang melakukan perilaku pencegahan dengan baik, tidak ditemukan kejadian akne vulgaris.

Dengan demikian dapat disimpulkan secara statistic $\mathrm{Ha}$ diterima dan Ho ditolak, atau terdapat hubungan perilaku pencegahan terhadap kejadian akne vulgaris pada siswa SMK Negeri Tanjungsari Lampung Selatan Tahun 2020.

Hernowo Anggoro Wasono ${ }^{1}$, Nopi Sani ${ }^{2}$, Yuyun Andriyani ${ }^{3}$

${ }^{1}$ Departemen Kedokteran Keluarga Universitas Malahayati

${ }^{2}$ Dosen Fakultas Kedokteran Universitas Malahayati

${ }^{3}$ Fakultas Kedokteran Universitas Malahayati. Email: Yuyunandriyani98@gmail.com 


\section{PEMBAHASAN}

Insidensi tertinggi terdapat pada perempuan antara umur 14-17 tahun dan pada laki-laki antara umur 16-19 tahun. Tetapi dapat pula timbul pada usia di atas 40 tahun dan penyakit ini dapat pula menetap pada usia lanjut. 10\% kasus didapat pada usia 30-40 tahun. Bentuk yang lebih berat dari akne terdapat pada kirakira 3\% laki-laki lebih jarang pada perempuan (Rahmawati, 2012).

Remaja dalam perkembangannya, dihadapkan oleh berbagai perubahan mencakup perubahan biologis dan psikologis. Perubahan biologis yang terdiri dari peruahan fisik merupakan pencetus yang berdampak pada tahap psikis. Perubahan kondisi fisik inilah yang berpengaruh pada kepercayaan diri. Penampilan fisik seperti wajah berjerawat yang tidak sesuai dengan gambaran ideal ketidakpuasan sehingga menimbulkan rasa kurang percaya diri (Ompi, 2016).

Pada waktu pubertas terdapat kenaikan dari hormon androgen yang beredar dalam darah yang dapat menyebabkan hyperplasia dan hipertrofi dari glandula sebasea sehingga tidak heran jika angka kejadian jerawat paling tinggi pada usia remaja. Sama halnya dengan peneliti dapatkan ditempat penelitian sebagian besar responden berada pada usia 15-16 tahun. Hal ini menunjukan bahwa pada saat umur 15-16 tahun tubuh sedang menuju proses hormone menuju kedewasaan yang berkaitan dengan system reproduksi akibat produksi hormon yang berlebihan akhirnyamenimbulkan acne vulgaris.

Pernyataan tersebut sesuai dengan hasil penelitian Widayanti
(2015) yang menyatakan bahwa umur remaja pada awal timbulnya akne vulgaris tampak kejadian tertinggi terjadi pada usia 14-16 tahun (60,00\%), kejadian terendah pada usia 17-20 tahun $(16,00 \%)$, dan pada usia $11-13$ tahun $(21,00 \%)$. Sedangkan sisanya yaitu $(3,00 \%)$ responden tidak menjawab pertanyaan. Riwayat keluarga kurang mempengaruhi akne vulgaris $(42,00 \%)$, perilaku membersihkan wajah secara teratur ( $89,00 \%$ ), faktor stress berpengaruh pada akne vulgaris $(54,00 \%)$, jenis makanan yang berpengaruh terhadap timbulnya akne vulgaris adalah kacang-kacangan $(35,00 \%)$, gorengan $(18,00 \%)$, makanan pedas $(3,00 \%)$, coklat $(2,00 \%)$, dan lainnya $(33,00 \%)$.

Menurut hasil Penelitian pada siswa SMK Negeri Tanjungsari Lampung Selatan Tahun 2020, didapatkan dengan rata-rata kejadian perilaku pencegahan yang tidak baik yaitu sebanyak 40 responden dengan persentase $(51,9 \%)$. Pencegahan Akne Vulgaris Pencegahan yang dapat dilakukan untuk menghindari jerawat adalah Menghindari terjadinya peningkatan jumlah lipid sebum dengan cara diet rendah lemak dan karbohidrat serta melakukan perawatan kulit untuk membersihkan permukaan kulit dari kotoran, menghindari terjadinya faktor pemicu, misalnya pola hidup sehat, olahraga teratur, hindari stres, penggunaan kosmetika secukupnya, menghindari memicu terjadinya kelenjar minyak berlebih misalnya minuman keras, pedas, dan rokok, memberikan informasi yang cukup pada penderita mengenai penyebab penyakit, pencegahan dan cara maupun lama pengobatannya serta prognosisnya (Wasitaatmadja, 2018).

Hernowo Anggoro Wasono ${ }^{1}$, Nopi Sani ${ }^{2}$, Yuyun Andriyani ${ }^{3}$

${ }^{1}$ Departemen Kedokteran Keluarga Universitas Malahayati

${ }^{2}$ Dosen Fakultas Kedokteran Universitas Malahayati

${ }^{3}$ Fakultas Kedokteran Universitas Malahayati. Email: Yuyunandriyani98@gmail.com 
Kebanyakan remaja khususnya pelajar SMA seringkali mengabaikan tentang kebersihan wajah mereka, dan lebih mementingkan kegiatan pribadi. Saat beraktivitas di luar ruangan, ekskresi keringat dan sebum meningkat ditambah terkena paparan debu, kotoran dan polusi menyebabkan kulit wajah menjadi kotor dan berminyak. Hal ini dapat menjadi tempat berkembangnya bakteri $P$. acnes yang merupakan tempat tumbuh pada folikel pilosebasea (Perry, 2006 \& Handa, 2012).

Berdasarkan hasil penelitian yang dilakukan oleh Rusydi (2016) di Padang diperoleh Hasil uji tingkat pengetahuan siswa-siswi SMAN 1 Padang tentang akne sebesar 82,1\% dikategorikan baik dan hasil uji sikap sebesar $83,2 \%$ dikategorikan baik. Hasil uji dengan menggunakan statistik chi-square, hubungan antara tingkat pengetahuan dan sikap pencegahan dengan kejadian akne didapatkan nilai $p=0,877(p>0,05)$ dan $p=0,036(p<0,05)$. Artinya, tidak terdapat hubungan antara tingkat pengetahuan dengan kejadian akne, dan terdapat hubungan antara sikap pencegahan dengan kejadian akne.

Etiologi yang pasti dari penyakit ini belum diketahui dengan pasti, namun dikatakan penyebabnya multifaktorial. Beberapa faktor yang dapat mempengaruhi timbulnya akne vulgaris adalah genetik, diet, hormon, musim atau cuaca, kosmetik, trauma dan infeksi, stress, obat-obatan dan jenis kulit.

Berdasarkan tabel di atas dengan perhitungan uji spearman didapatkan tingkat signifikansi sebesar 0,000 yang artinya lebih kecil dari nilai $\mathrm{p}=0,05$ dengan nilai $\mathrm{rxy}=$ 0,666 yang artinya berada pada interval 0,600-0,799 masuk kategori hubungan yang kuat (Sugiyono, 2009) dan mempunyai arah korelasi negative. Artinya hubungan yang tidak searah antara variabel perilaku pencegahan terhadap kejadian akne vulgaris, artinya siswa yang melakukan perilaku pencegahan dengan baik, tidak ditemukan kejadian akne vulgaris. Akne vulgaris dapat menimbulkan rasa ketidaknyamanan dan gangguan konsep diri bagi orang yang mengalami. Konsep diri adalah bagaimana seseorang memandang dirinya sendiri sehingga memiliki pengaruh yang kuat terhadap psikologis. Pandangan terhadap diri sendiri secara realistik, sikap menerima dan dapat menyukai apa yang ada pada dirinya mempengaruhi kecemasan dan harga diri. Penelitian terdahulu menyatakan 56,3\% penderita akne vulgaris memiliki dampak psikologis ringan-sedang dan 14,5\% berdampak besar. Karena banyak faktor sebagai penyebab acne vulgaris maka penanganan yang menyeluruh dapat membantu mempercepat penyembuhan dan mencegah kekambuhan. Selain terapi kulit secara medik diperlukan juga psikoterapi. Penambahan psikoterapi pada pasien acne vulgaris dapat menurunkan angka kambuh. Dengan relaksasi dapat meningkatkan daya tahan kulit dan aliran darah ke kulit meningkat. Kadang-kadang diperlukan psikofarmakologi untuk menurunkan kecemasan dan depresinya yaitu dengan anti cemas maupun anti depresi (Syamsuhadi dan Aliyah, 2002). Maka dari itu perilaku pencegahan sangat dibutuhkan untuk

Hernowo Anggoro Wasono ${ }^{1}$, Nopi Sani ${ }^{2}$, Yuyun Andriyani ${ }^{3}$

${ }^{1}$ Departemen Kedokteran Keluarga Universitas Malahayati

${ }^{2}$ Dosen Fakultas Kedokteran Universitas Malahayati

${ }^{3}$ Fakultas Kedokteran Universitas Malahayati. Email: Yuyunandriyani98@gmail.com 
menghindari timbulnya akne vulgaris pada remaja.

\section{KESIMPULAN}

1. Terdapat hubungan signifikan perilaku pencegahan terhadap kejadian akne vulgaris dengan korelasi negative. Artinya hubungan yang tidak searah antara variabel perilaku pencegahan terhadap kejadian akne vulgaris, artinya siswa yang melakukan perilaku pencegahan dengan baik, tidak ditemukan kejadian akne vulgaris.

2. Distribusi frekuensi responden berdasarkan kejadian akne vulgaris sebanyak 45 responden dengan persentase $(58,4 \%)$.

3. Distribusi frekuensi responden berdasarkan perilaku pencegahan , perilaku pencegahan yang tidak baik sebanyak 40 responden dengan persentase $(51,9 \%)$.

\section{DAFTAR PUSTAKA}

Ana dan Jannah R., 2018. Hubungan Pengetahuan tentang akne vulgaris dengan perilaku pencegahan Akne Vulgaris Pada Remaja Di MAN 2 Kabupaten Ponorogo. Skripsi (S1) thesis, Universitas Muhammadiyah Ponorogo.

Djuanda A. 2016., Ilmu penyakit kulit dan kelamin. Sri linuwih sw menaldi, Ed-7. Jakarta.

Goldsmith, L. A. (Eds)., 1971-2012. Fitzpatrick's Dermatology in General Medicine (2th vol.). New York : McGraw-Hill.
Gollnick H. dan Dreno B., 2015. Acne and management: Pathophysiology and management of acne. Journal European Academy of Dermatology and Venereology. 29(4): 1-2.

Latifah, Sofia \& Kurniawaty, E., 2015. Stres dengan Akne Vulgaris. Fakultas Kedokteran

Unila : Lampung.

Masterson $\quad$ K.N., 2018. Pathophysiology, assessment, and standard treatment options.

Menaldi, S. L. (Eds)., 1987-2018. Ilmu Penyakit Kulit dan Kelamin. Jakarta : FK UI

Notoadmodjo, S., 2014. Promosi kesehatan dan ilmu perilaku. Jakarta : Rineka Cipta.

Notoatmodjo, S., 2014, Ilmu Perilaku Kesehatan. Jakarta : Rineka Cipta.

Notoatmodjo, S,. 2017, metodelogi penelitian kesehatan. Jakarta : Rineka Cipta.

PERDOSKI 2017. Panduan praktik klinis bagi dokter spesialis kulit dan kelamin di Indonesia 2017. Jakarta

Primantiko, I., 2018. Tingkat Pengetahuan dan Perilaku Masyarakat Tentang Makanan Berkolesterol Tinggi dengan Terjadinya Hipertensi pada Puskesmas Yosodadi Tahun 2018. Skripsi. Fakultas

Hernowo Anggoro Wasono ${ }^{1}$, Nopi Sani ${ }^{2}$, Yuyun Andriyani ${ }^{3}$

${ }^{1}$ Departemen Kedokteran Keluarga Universitas Malahayati

${ }^{2}$ Dosen Fakultas Kedokteran Universitas Malahayati

${ }^{3}$ Fakultas Kedokteran Universitas Malahayati. Email: Yuyunandriyani98@gmail.com 
Kedokteran

Malahayati. Bandar

Lampung.

Rahmawati, Nur Intan., 2017. Hubungan Antara Tingkat Pengetahuan dan Sikap Remaja Tentang Jerawat di SMK Al-Huda Kebumen. STIKES Muhammadiyah Gombong.

Rusydi D.M., 2016. Hubungan Tingkat Pengetahuan dan Sikap Pencegahan Dengan Kejadian Akne Vulgaris Pada Siswa-siswi SMAN 1 Padang. Thesis. Jurnal Universitas Andalas.

Sampelan G.M., Pangemanan D., dan Kundre M.R., 2017. Hubungan Timbulnya Kecemasan Pada Remaja Di SMPN 1 Likupan Timur. e-Journal Keperawatan (e-Kp). 5(1)

Sampelan MG, Pangemanan D, Kundre RM., 2017. Hubungan timbulnnya acne vulgaris dengan tingkat kecemasan pada remaja di SMPN 1 Likupang Timur. $\quad \mathrm{E}$ journal keperawatan 5(1).

Sylvia \& Mayestika, R., 2017. Hubungan pemakaian bedak dengan angka kejadian akne vulgaris pada siswi SMAN 1 Padang. Universitas Andalas, Padang.
Tan, J. K. L., dan Bhate, K., 2015. A Global Perspective On The Epidemiology of Acne. British Journal of Dermatology.

Wardhani, H., \& Sulistiyaningsih, R., 2019. Artikel Tinjauan : Tanaman Obat/Herbal Sebagai Terapi Akne Vulgaris. Jurnal Farmaka. Universitas Padjadjaran.

Widayanti., $2015 . \quad$ Persepsi Mahasiswa Fakultas Kedokteran Universitas Diponegoro Terhadap Akne Vulgaris. Jurnal MEDIA MEDIKA MUDA. 4(2) : 176-188.

Winardi, R., \& Wahab, S., 2017. Hubungan Tingkat Kecemasan Dengan Timbulnya Acne Vulgaris Pada Mahasiswa Pendidikan Dokter Universitas Hasanuddin Angkatan 20142017. Skripsi. Universitas Nusantara PGRI Kediri.

Yeti, Rahma., 2016. Analisis Konsep Diri Mahasiswa Keperawatan Yang Mengalami Akne Vulgaris Di Universitas Islam Negeri Alaudin Makassar. Skripsi. Fakultas Kedokteran dan Ilmu Kesehatan Universitasislam Negeri Alauddin Makassar. 